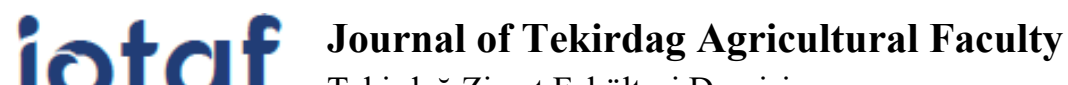

Tekirdağ Ziraat Fakültesi Dergisi

\section{F2 Kademesindeki Oleik ve Yarı Oleik Aspir Genotiplerinin (Carthamus tinctorius L.) Bazı Morfolojik ve Teknolojik Karakterlerinin Belirlenmesi}

\author{
Determination of Some Morphological and Technological Characters in $F_{2}$ Generation of \\ Oleic and Mid-Oleic Type Safflower Genotypes (Carthamus tinctorius L.)
}

\section{Emrullah CULPAN ${ }^{*}$, Burhan ARSLAN ${ }^{2}$}

\section{$\ddot{O} \mathbf{z}$}

Tekirdağ Namık Kemal Üniversitesi Ziraat Fakültesi Tarla Bitkileri Bölümü araştırma ve uygulama arazisinde 2018, 2019 ve 2020 yıllarında yürütülen bu araştırmada, melezleme ile geliştirilmiş olan bazı oleik ve yarı oleik aspir genotiplerinin tarımsal ve teknolojik özelliklerinin belirlenmesi amaçlanmıştır. Bu doğrultuda Dinçer 5-181 aspir çeşidi ile PI 603208 genotipinin melezlenmesinden elde edilmiş olan 11 adet $F_{2}$ kademesindeki melez genotip materyal olarak kullanılmış, iki standart oleik aspir çeşidi ile bu melezlerin ebeveynleri (Dinçer 5-18-1, PI 603208, Olas ve Asol) karşılaştırılmıştır. Tarımsal ve teknolojik özelliklerinin saptanması amacıyla araştırmada, bitki boyu (cm), dal sayısı (adet) tabla sayısı (adet), tabla çapı (cm), 1000 tane ağırlığı $(\mathrm{g})$, tohum verimi $\left(\mathrm{kg} \mathrm{da}^{-1}\right)$, kabuk oranı (\%), yağ oranı (\%), yağ verimi $\left(\mathrm{kg} \mathrm{da}^{-1}\right)$ ve yağ asitleri kompozisyonu (\%) gibi karakterler ölçülmüştür. Araştırmadan elde edilen bulgulara göre melez genotiplerin tohum verimi değerleri 120.73-187.80 kg da-1 , yağ oranı değerleri \% 31.67-36.49 ve yağ verimi değerleri 40.43-63.92 $\mathrm{kg} \mathrm{da}^{-1}$ arasında değişerek geniş bir varyasyon göstermiştir. Araştırmada melez genotiplerden en yüksek yağ oranı EC/ol-7 genotipinden (\% 36.49) elde edilirken, en yüksek tohum verimi ve yağ verimi EC/ol-8 genotipinden elde dilmiştir (sırasıyla 187.80 ve $63.92 \mathrm{~kg} \mathrm{da}^{-1}$ ). Melez genotipler arasında en yüksek oleik yağ asidi içeriği ise EC/ol-11 genotipinden elde edilmiştir (\% 61.79). Yağ oranı, tohum verimi ve oleik yağ asidi içeriği bakımından belirlenen sslah amaçları doğrultusunda $F_{2}$ kademesindeki 5 adet genotipin (EC/ol 5, EC/ol 6, EC/ol 7, EC/ol 8 ve EC/ol 11) diğer genotiplerden üstün olduğu belirlenmiştir. Diğer genotiplerden de ilerleyen kademelerde $\left(\mathrm{F}_{3}\right.$ ve $\left.\mathrm{F}_{4}\right)$ hem stabil olanlar hem de ümitvar olanlar belirlenecektir.

Anahtar Kelimeler: Aspir, Yağ oranı, Tohum verimi, Melezleme, Oleik asit

\footnotetext{
1*Sorumlu Yazar/Corresponding Author: Emrullah CULPAN, Tekirdağ Namık Kemal Üniversitesi, Ziraat Fakültesi, Tarla Bitkileri Bölümü, 59030, Süleymanpaşa, Tekirdağ. E-mail: eculpan@nku.edu.tr (iD) OrcID: 0000-0002-0702-7121

${ }^{2}$ Burhan ARSLAN, Tekirdağ Namık Kemal Üniversitesi, Ziraat Fakültesi, Tarla Bitkileri Bölümü, 59030, Süleymanpaşa, Tekirdağ. E-mail: barslan@nku.edu.tr (iD) OrcID: 0000-0002-9728-4059.

Atıf/Citation: Culpan, E., Arslan, B. F Kademesindeki Oleik ve Yarı Oleik Aspir Genotiplerinin (Carthamus tinctorius L.) Bazı Morfolojik ve Teknolojik Karakterlerinin Belirlenmesi. Tekirdağ Ziraat Fakültesi Dergisi, 19 (1), 156-165.

CBu çalışma Tekirdağ Namık Kemal Üniversitesi tarafından Creative Commons Lisansı (https://creativecommons.org/licenses/by-nc/4.0/) kapsamında yayınlanmıştır. Tekirdağ 2022 


\begin{abstract}
In this study, was conducted in 2018, 2019 and 2020 at Tekirdağ Namık Kemal University Agriculture Faculty Department of Field Crops, it was aimed to determine morphological and technological traits of some oleic and mid-oleic type safflower genotypes developed by cross breeding. For this purpose, $11 \mathrm{~F}_{2}$ hybrid genotypes obtained from a cross between Dinçer 5-18-1 cultivar and PI 603208 genotype were used as material and compared to two standard oleic local cultivars and parents of these hybrids (Dinçer 5-18-1, PI 603208, Olas ve Asol). In study to determine the agricultural and technological traits, plant height $(\mathrm{cm})$, branch number, head number, head diameter $(\mathrm{cm}), 1000$ seed weight $(\mathrm{g})$, seed yield $\left(\mathrm{kg} \mathrm{da}^{-1}\right)$, hull ratio $(\%)$, oil content $(\%)$, oil yield $\left(\mathrm{kg} \mathrm{da}^{-1}\right)$ and fatty acid composition (\%) were investigated. According to research findings, seed yield values of hybrid genotypes changed between $120.73-187.80 \mathrm{~kg} \mathrm{da}^{-1}$, oil content values $31.67-36.49 \%$ and oil yield values 40.43-63.92 $\mathrm{kg} \mathrm{da}^{-1}$ and showed a wide variation. The highest oil content among hybrid genotypes were obtained from the EC/ol-7 genotype (36.49\%), while the highest seed yield and oil yield among genotypes were obtained from the EC/ol-8 genotype (187.80 and $63.92 \mathrm{~kg} \mathrm{da}^{-1}$ respectively). The highest oleic oil content among hybrid genotypes was obtained from the EC/ol-11 genotype (61.79\%). In this study, it was determined that 5 genotypes in terms of oil content, seed yield and oleic acid composition (EC/ol 5, EC/ol 6, EC/ol 7, EC/ol 8 and EC/ol 11) are superior of the other genotypes in $\mathrm{F}_{2}$ generation. In addition, with the other genotypes, both stable and hopeful ones will be determined the next generations $\left(\mathrm{F}_{3}\right.$ and $\left.\mathrm{F}_{4}\right)$.
\end{abstract}

Keywords: Safflower, Oil content, Seed yield, Hybridization, Oleic acid 


\section{Giriş}

Yağ bitkilerinde klasik bitki ıslahı ve bitki genetik mühendisliği uygulamaları ile geleneksel yağ asitleri komposizyonları değiştirilerek yeni ve farklı yağların elde edilmesi 20. yüzyılın son çeyreğinde başlamış ve 21 . yüzyılda daha da önem kazanmıştır (Baydar, 2016). Aspir (Carthamus tinctorius L.), Asteraceca familyasına dahil, 2n=24 kromozomlu, Güney Asya orijinli önemli bir yağ bitkisidir. Aspir tohumlarında \%25-45 arasında yağ bulunmakta, bu yağın yaklaşık \%90'ı doymamış yağ asitlerinden (oleik ve linoleik asit) oluşmaktadır (Johnson ve ark., 1999).

Ülkemizde yerli tohumluk olarak tescil edilmiş 15 adet (Yenice 5-38, Dinçer 5-18-1, Remzibey-05, Balc1, Linas, Olas, Göktürk, Asol, Hasankendi, Yektay, Zirkon, Olein, Koç, Safir ve Servetağa) aspir çeşidi vardır (Arslan ve Culpan, 2020). Bu aspir çeşitlerinden yalnızca Olas, Asol ve Olein çeşitleri oleik yağ asidi içeriğine sahiptir. Ülkemizde görülen farklı iklim ve toprak özellikleri ve her yıl giderek artan bitkisel yağ açığına bağlı olarak çeşit sayısının artırılmasına ihtiyaç duyulmaktadır. Çeşit sayısının artırılmasının yanı sıra yüksek oleik asitli (High-Oleic) aspir çeşitlerinin de geliştirilmesine ihtiyaç vardır. Bunun yanında oleik asit içeriği yüksek olan yağların önem kazanmasıyla birlikte, yüksek linoleik asit içeren çeşitlere (HL) ilaveten yüksek oleik asitli (HO) aspir çeşitlerin de geliştirilmesi büyük önem taşımaktadır (Baydar, 2016).

Oleik asit $\left(\mathrm{C}_{18: 1}\right)$, toplam 18 karbonlu, tek bir çift bağ taşıyan, tekli doymamış bir yağ asididir. Oleik asit aynı zamanda omega-9 olarak da bilinmektedir. Oleik asit içeriği yüksek olan yağlar, özgül ağırlıkları düşük olmasından dolayı oldukça hafiftir. Bu nedenle pişirme ve kızartma yağı olarak çok uygundur. Yüksek oleik asit içeren yağların linoleik asit içeren yağlara göre raf ömürleri daha uzundur. Buna ilaveten oksidasyona daha dayanıklı olması, kızartma yağı özelliklerinin üstün olması, kullanım sayısının daha fazla ve tortu bırakma derecesinin daha düşük olması gibi pek çok avantajı oleik asitçe zengin yağlara karşı trendi arttırmıştır (Baydar, 2016). Ayrıca son yıllarda endüstriyel kullanıma ve biyodizele uygunluğu bakımından yüksek oleik asit tipi yağlara olan talebin de giderek arttığı görülmektedir. Çünkü oleik asit gibi uzun zincirli, ancak az doymamış yağ asidi içeren yağlar biyodizel üretimi için uygundur (Pinto ve ark., 2005).

Dünyanın ilk oleik asitçe zengin aspir tipi 1966 yılında ABD'de geliştirilen 'UC-1' çeşididir. Hindistan orijinli bir introdüksiyon materyalinde Paul Knowles tarafından tespit edilen oleik asitçe zengin bir mutant sayesinde $o l$ alleli kültür çeşitlerine aktarılarak oleik asitçe zengin (HO) aspir çeşitleri geliştirilebilmiştir (Knowles ve Hill, 1964). Ülkemizde ise oleik asit bakmından zengin ilk aspir çeşidi Trakya Tarımsal Araştırma Enstitüsü tarafından 2015 yllında tescil ettirilmiş olan 'Olas' çeşididir (Babaoğlu ve Güzel, 2015).

Ülkemizde tescilli aspir çeşitlerinden Olas, Asol ve Olein dışındakiler yüksek linoleik asit (\%75-80) içermektedir. Oysa dünyada yeni gelişen trend yüksek oleik asit içeren aspir çeşitlerini geliştirmektir. Örneğin ABD'de hem yüksek linoleik asit hem de yüksek oleik asit içeren aspir çeşitleri islah edilmiştir. Bergman ve ark., (2000), geliştirdikleri Montola 2001 çeşidinde toplam doymuş yağ asitleri oranının \%7'den az, oleik asit oranın oranının \% 80'den fazla olmasını amaçlamışlardır. Araştırıcılar, 2003 yılında tescil ettirdikleri Montola 2001 çeşidinin Montola 2000 çeşidinden daha yüksek oleik aside ve daha düşük linoleik asite sahip olduğunu bildirmişlerdir. Montola 2000 çeşidinde \% 80.8 olan oleik asit oranının Montola 2001 çeşidinde \% 83.4'e yükseltildiğini ve \% 12.3 olan linoleik asit oranının ise \% 9.2'e düşürüldüğünü belirtmişlerdir (Bayramin, 2006).

$\mathrm{Bu}$ araştırmada, dikensiz bir çeşit olan linoleik tip Dinçer 5-18-1 aspir çeşidi ile yüksek yağ içeriğine sahip olan oleik tip dikenli PI 603208 aspir genotipi giberellik asit ile kimyasal polen kısırlığı yöntemi uygulanarak melezlenmiş ve ilk açılım kuşağı olan $\mathrm{F}_{2}$ kademesindeki döllerden yüksek tohum verimi ve yağ oranına sahip oleik yağ asidi içeren genotipler elde edilmeye çalışılmıştır. 


\section{Materyal ve Metot}

\subsection{Araştırma yerinin ilkim ve toprak özellikleri}

Çalışma, Tekirdağ Namık Kemal Üniversitesi Ziraat Fakültesi Tarla Bitkileri Bölümü uygulama arazisinde yazlık ekim yapılarak, 2018-2020 yılları arasında tek lokasyonda yürütülmüştür. Araştırma yerinin toprakları killi bir bünyeye sahip olup, pH'sı hafif alkali (7.07) ve organik madde bakımından zayıftır (\% 0.91). Kireç içeriği düşük olan toprakların (\%2.40), fosfor seviyesi de düşük $(3.98 \mathrm{~kg} / \mathrm{da})$ olup, tuzluluk problemi yoktur. $\mathrm{F}_{2}$ genotiplerinin yetiştirildiği 2020 yılında ortalama sıcaklık değerleri uzun yıllar ortalamasına yakındır. Toplam yağış miktarı ise $239.60 \mathrm{~mm}$ ile uzun yıllar ortalamaları toplamından bir miktar fazla iken, ortalama oransal nem değerleri ise uzun yıllar ortalamasından yaklaşık \% 3 oranında düşüktür (Tablo 1). Aspir bitkisi iklim ve toprak istekleri bakımından seçici değildir. Bu bağlamda araştırma yerinin iklim ve toprak özellikleri aspir tarımı için yeterli ve uygun seviyededir.

Tablo 1. Tekirdăg (Süleymanpaşa)'ın aspir yetiştirme aylarına ait 2020 yılı ve uzun yıllar iklim verileri*

Table 1. 2020 and long years climate data of the safflower growing seasons of Tekirdağ (Süleymanpaşa)*

\begin{tabular}{lcccccc}
\hline \multirow{2}{*}{ Aylar } & \multicolumn{2}{c}{ Ortalama Sicaklık $\left({ }^{\mathbf{0}} \mathbf{C}\right)$} & \multicolumn{2}{c}{ Toplam Yağıs $(\mathbf{m m})$} & \multicolumn{2}{c}{ Oransal Nem (\%) } \\
& 2020 & Uzun Yillar & 2020 & Uzun Yillar & 2020 & Uzun Yillar \\
\hline Mart & 9.6 & 7.3 & 26.1 & 54.4 & 74.6 & 77.9 \\
Nisan & 10.7 & 11.7 & 43.6 & 41.0 & 70.9 & 77.0 \\
Mayis & 16.6 & 16.7 & 96.4 & 36.7 & 73.0 & 76.3 \\
Haziran & 21.3 & 21.1 & 67.3 & 38.0 & 71.3 & 72.3 \\
Temmuz & 24.6 & 23.6 & 0 & 24.8 & 65.6 & 68.7 \\
Ağustos & 25.0 & 23.8 & 6.2 & 15.4 & 66.4 & 69.2 \\
Ort./Top. & $\mathbf{1 7 . 9 7}$ & $\mathbf{1 7 . 3 7}$ & $\mathbf{2 3 9 . 6 0}$ & $\mathbf{2 1 0 . 3 0}$ & $\mathbf{7 0 . 3 0}$ & $\mathbf{7 3 . 5 7}$ \\
\hline
\end{tabular}

*Tekirdağ Meteoroloji İstasyonu Verileri

\subsection{Materyal}

Araştırmada, Eskişehir Geçit Kuşağı Tarımsal Araştırma Enstitüsü tarafından geliştirilmiş olan Dinçer 5-18-1 çeşidi, Trakya Tarımsal Araştırma Enstitüsü tarafından geliştirilmiş olan Olas ve Asol çeşidi ile Amerika Birleşik Devletleri Tarım Bakanlığı'ndan (USDA) temin edilen PI 603208 nolu genotip materyal olarak kullanılmıştır. Melezlemede materyal olarak kullanılmış olan Dinçer 5-18-1 çeşidi dikensiz yapıya sahip olup linoleik tip, kırmızı çiçekli ve yağ oranı \%25-30 civarındadır. PI 603208 genotipi ise dikenli yapıya sahip, oleik, sarı çiçekli ve yağ oranı \%35-37 arasındadır.

\subsection{Yöntem}

2018 yılında Dinçer 5-18-1 çeşidi (†) ile PI 603208 genotipi ( $\left(^{\Uparrow}\right)$ melezlenmiş ve bu melezlemeden elde edilen $\mathrm{F}_{1}$ genotipleri bir sonraki yıl ekilerek $\mathrm{F}_{2}$ genotipleri elde edilmiştir. 18.04.2018 tarihinde $5 \mathrm{~m}$ uzunluğundaki sıralara $50 \mathrm{~cm}$ sıra arası ile ekilmiş olan Dinçer 5-18-1 ve PI 603208 ebeveynleri arasında haziran ayı içerisinde giberellik asit ile kimyasal erkek kısırlığ 1 (ch-ms) oluşturularak melezleme yapılmıştır (Erbaş, 2007). Melezlenmiş olan her tabladan elde edilen tohumlar 01.08.2018 tarihinde ayrı ayrı hasat edilmiş ve $+4{ }^{0} \mathrm{C}$ 'de buzdolabında muhafaza edilmiştir. 19.04.2019 tarihinde, $F_{1}$ tohumları ekilerek $F_{1}$ bitkileri yetiştirilmiş ve çiçeklenme dönemi boyunca dikensiz olduğu tespit edilen bitkiler (melez olmayanlar) sıralardan uzaklaştırılmıştır. Böylece sıralarda gerçek melezlerin (\%100) kalması sağlanmıştır. Aspirde dikenlilik karakteri dikensizlik üzerine baskındır ve kalıtımı tek bir gen tarafından kontrol edilmektedir (Baydar ve Erbaş, 2016). Gerçek melez $F_{1}$ genotiplerinden elde edilmiş bitkiler izole edilerek kendilenmiş, tarımsal ve teknolojik özellikleri belirlenecek 11 adet $F_{2}$ genotipi oluşturulmuştur. Oluşturulmuş bu genotipler standart çeşitler ve ebeveynleriyle (Dinçer 5-18-1, PI 603208, Olas ve Asol) karşılaştırılmıştır.

18.03.2020 tarihinde 11 adet $\mathrm{F}_{2}$ genotipi, standart çeşitler ve ebeveynler kullanılarak kurulmuş deneme, 'Tesadüf Blokları Deneme Deseni'ne göre 3 tekrarlamalı olarak yürütülmüştür. Denemede her genotip $5 \mathrm{~m}$ uzunluğundaki parsellere sıra arası $20 \mathrm{~cm}$ (Arslan ve Culpan, 2020), ekim derinliği 3-4 cm olacak şekilde 5 sıra halinde elle ekilmiştir. Toprak analizi sonucuna göre dekara $12 \mathrm{~kg}$ saf azot ve $6 \mathrm{~kg}$ saf fosfor verilmiştir. Azotun yarısı ekimle beraber diğer yarısı bitkiler sapa kalktığında, fosforun ise tamamı ekimle birlikte verilmiştir. Hasat 11.08.2020 tarihinde elle yapılmıştır. Parsellerden tesadüfen seçilen 10 bitkide bazı tarımsal ve teknolojik ölçümler 

yapılmıştır. Bu kapsamda araştırmada, bitki boyu (cm), dal sayısı (adet) tabla sayısı (adet), tabla çapı (cm), 1000 tane ağırlığ $(\mathrm{g})$, tohum verimi $\left(\mathrm{kg} \mathrm{da}^{-1}\right)$, kabuk oranı $(\%)$, yağ oranı $(\%)$, yağ verimi $\left(\mathrm{kg} \mathrm{da}^{-1}\right)$ ve yağ asitleri kompozisyonu (\%) gibi karakterler ölçülmüştür.

Araştırmada yă̆ içeriği, Nükleer Manyetik Rezonans (NMR) cihazında \% olarak okutularak belirlenmiştir. Tohumlar $70{ }^{\circ} \mathrm{C}$ 'de 48 saat etüvde bekletilerek nemi giderilmiştir. Nemi alınan 4'er g tohum NMR cihazında her parselde 3 okuma yapılarak \% yağ oranı ortalaması hesaplanmıştır. Yağ asitleri kompozisyonu ise alev iyonlaşma detektörüne (FID-Flame Ionization Dedector) sahip gaz kromotografisi (Agilent 7820A) cihazında belirlenmiştir. Yağların metillendirilmesi için soğuk pres tekniği ile elde edilmiş $1 \mathrm{mg}$ ham yağ üzerine $0.5 \mathrm{ml}$ metanollü potasyum hidroksit koyulup çalkalanmıştır. Daha sonra bu karışımın üzerine $10 \mathrm{ml}$ n-heptan eklenerek çözelti tekrar çalkalanmış ve gliserolün ayrılmasıyla çözelti bulanıklaşmıştır. 1 saat bekledikten sonra gliserolün çökelmesiyle beraber oluşan faz ayrımında üst faz metil esterleri alınarak Gaz Kromatografi (GC) cihazına direk olarak verilmiş ve analiz yapılmıştır. Yağ asitlerine ilişkin kromatogramlar elde edilerek palmitik (C16:0), stearik $\left(\mathrm{C}_{18: 0}\right)$, oleik $\left(\mathrm{C}_{18: 1}\right)$ ve linoleik $\left(\mathrm{C}_{18: 2}\right)$ yağ asitlerinin \% oranları tespit edilmiştir. Elde edilen kromotogramlardaki pikler ticari standart yă asidi metil ester karışımına (Sigma, Supelco® 37 Component FAME Mix) göre isimlendirilmiştir. GC cihazının çalışma koşulları Tablo 2'de verilmiştir.

Tablo 2. GC cihazının çalışma koşulları

Table 2. Operating conditions of the GC device

\begin{tabular}{|c|c|}
\hline Cihaz & Agilent 7820A GC \\
\hline Dedektör Tipi & FID - Alev İyonizasyon Dedektörü \\
\hline Kullanılan Kolon & $\mathrm{J} \& \mathrm{~A} 112-88 \mathrm{~A} 7(100 \mathrm{~m} \times 0.25 \mathrm{~mm}, 0.2 \mu \mathrm{m})$ \\
\hline Enjektör Sicaklığı & $250{ }^{\circ} \mathrm{C}$ \\
\hline Dedektör Sicaklığ 1 & $280{ }^{\circ} \mathrm{C}$ \\
\hline \multirow[t]{2}{*}{ Enjektör Kapasitesi } & $1 \mu \mathrm{m}$ \\
\hline & Hidrojen $(40 \mathrm{~mL} / \mathrm{dk})$ \\
\hline \multirow[t]{2}{*}{ Gaz Hizları } & Hava $(450 \mathrm{~mL} / \mathrm{dk})$ \\
\hline & Helyum $(30 \mathrm{~mL} / \mathrm{dk})$ \\
\hline Firın Sicaklığı & $\begin{array}{l}120^{\circ} \mathrm{C} \text { 'de } 1 \mathrm{dk} \text { bekledikten sonra } 175^{\circ} \mathrm{C} \text { 'ye } 10^{\circ} \mathrm{C} / \mathrm{dk} \text { artışla ulaşıyor. } 175^{\circ} \mathrm{C} \text { ' de } 10 \\
\mathrm{dk} \text { bekliyor. } 5^{\circ} \mathrm{C} / \mathrm{dk} \text { artışla } 210^{\circ} \mathrm{C} \text { 'ye ulaşıyor. Bu sicaklıkta } 5 \mathrm{dk} \text { bekliyor. } 5^{\circ} \mathrm{C} / \mathrm{dk} \\
\text { artışla } 230^{\circ} \mathrm{C} \text { 'e ulaşıyor. Bu sıcaklıkta da } 5 \mathrm{dk} \text { bekliyor. }\end{array}$ \\
\hline
\end{tabular}

\subsection{Verilerin Değerlendirilmesi}

Araştırma sonucundan elde edilen veriler varyans analizine tabi tutulmuştur. Ortalamalar arasındaki farklılıkların önem düzeyini belirlemek için Duncan Testi (\%5) kullanılmıştır. Verilerin analizinde TARIST istatistiki analiz programı kullanılmıştır.

\section{Araştırma Sonuçları ve Tartışma}

Melez aspir genotiplerinin bitki boyu değerleri 76.78-81.40 cm arasında değişmiştir. En uzun bitki boyuna EC/ol-9 genotipi sahip olurken $(81.40 \mathrm{~cm})$, ebeveynlerde ise en uzun bitki boyu Dinçer 5-18-1 çeşidinden elde edilmiştir $(80.80 \mathrm{~cm})$. Aspirde bitki boyu eklemeli genler tarafından kontrol edildiği için bitki boyunda geniş bir varyasyon görülmektedir (Pahlavani ve ark., 2007). Aspirde ideal bitki boyunun 60-80 cm arasında olduğu ve bitki boyu arttıkça yatma sorunu ortaya çıktığı bildirilmiştir (Weiss, 2000; Emongor, 2010). Yapılan araştırmalarda aspirde bitki boyunun iklim koşulları, çeşit, ekim mesafeleri ve ekim normuna göre önemli ölçüde değişiklik gösterdiği bildirilmiştir (Köse ve Bilir, 2017; Gürsoy ve ark., 2018). Arslan ve Culpan (2020) 14 adet F2 kademesindeki aspir genotipinde bitki boyunun 58.93-73.92 cm arasında değiştiğini ve geniş bir varyasyon gösterdiğini bildirmişlerdir.

Dal sayısı bakımından melez genotipler incelendiğinde en fazla dal sayısı 7.78 adet/bitki ile EC/ol-6 genotipinden elde edilmiştir (Tablo 3). Yerel çeşitler ve ebeveynler incelendiğinde en fazla dal sayısı baba ebeveyn olan PI 603208 genotipinden elde edilmiştir (8.35 adet/bitki). Aspir bitkisinde dal sayısı çevre koşulları, ekim mesafeleri ve genetik faktörlerden etkilenen bir özelliktir (Pearl ve ark., 2014; Gürsoy ve ark., 2018). Erbaş (2012) aspirde dal sayısı için kalıtım derecesinin \% 64.2 oranında olduğunu bildirmiştir. Aspirde ideal dal sayısının 6-8 
adet/bitki olduğu rapor edilirken (Weiss, 2000), yapılan bazı araştırmalarda bitki başına dal sayısının, 5.5-6.1 adet (Kızıl, 2002), 3-9 adet (Çamaş ve Esendal, 2006), 8.48-12.78 adet (Paşa, 2008), 6.50-10.13 adet (Adalı ve Öztürk, 2016), 3.94-9.17 adet (Arslan ve Culpan, 2018) olduğu bildirilmiştir.

Aspirde tabla sayısı ve tohum verimi arasında olumlu bir ilişki vardır ve tabla sayısı en önemli sslah kriterlerinden biridir (Weiss, 2000; Tunçtürk ve ark., 2005). Genotiplerin tabla sayısı değerleri 11.23-13.48 adet arasında değişmiş fakat bu fark istatistiki olarak önemli bulunmamıştır (Tablo 3). Erbaş (2007) Isparta koşullarında 48 aspir genotipinde tabla sayısının 7.2-18.0 adet/bitki olduğunu, Katar ve ark. (2014) yaptıkları çalışmada aspirde tabla sayısının 12.5-18.7 adet/bitki arasında değiştiğini belirlerken, Atan ve ark. (2019) bitki başına tabla sayısını 11.53-16.20 adet arasında belirlemiş, Arslan ve Culpan (2020) ise 8.05-14.50 adet/bitki olduğunu bildirmişlerdir.

Araştırmada en yüksek tabla çapı PI 603208 genotipi ve Olas çeşidinden elde edilmiştir (sırasıyla 2.54 ve 2.51 $\mathrm{cm})$. Melez genotiplerde ise en yüksek tabla çap $2.49 \mathrm{~cm}$ ile EC/ol-5 ve EC/ol-6 genotiplerinde belirlenmiştir (Tablo 3). Çamaş ve ark. (2005), yaptıkları çalışmada tabla çapı ile tohum verimi arasında pozitif bir korelasyon olduğunu bildirmiş̧lerdir. Hatipoğlu ve ark. (2012), yaptıkları üç yıllık çalışma neticesinde aspirde en yüksek tabla çapını $2.07 \mathrm{~cm}$, en düşük tabla çapını ise $1.63 \mathrm{~cm}$ olarak belirlerken, Aslantaş ve Akınerdem (2020) tabla çapını $2.06-2.25 \mathrm{~cm}$ arasında, Şenateş ve Erbaş (2020) ise Gelendost- $2 \times$ Montola 2000 melezi hatlarının tabla çapını 1.87-2.58 cm arasında, Gelendost-2 $\times$ W6 9822 melezi hatlarının tabla çapını 18.2-2.50 cm arasında, Gelendost-2 $\times$ Centennial melezi hatlarının tabla çapını ise $2.03-2.57 \mathrm{~cm}$ arasında belirlemişlerdir. Elde edilen sonuçlar literatürde belirtilen araştırıcıların sonuçları ile uyum içindedir.

Tablo 3. Aspir genotip ve melezlerinin bazı tarımsal ve kalite özellikleri

Tablo 3. Agricultural and quality traits of safflower genotypes and hybrids

\begin{tabular}{|c|c|c|c|c|c|c|c|c|c|c|}
\hline No & Genotipler & $\begin{array}{l}\text { Bitki } \\
\text { Boyu } \\
(\mathrm{cm})\end{array}$ & $\begin{array}{c}\text { Dal } \\
\text { Sayısı } \\
\text { (adet) }\end{array}$ & $\begin{array}{l}\text { Tabla } \\
\text { Sayısı } \\
\text { (adet) }\end{array}$ & $\begin{array}{l}\text { Tabla } \\
\text { Çapı } \\
(\mathrm{cm})\end{array}$ & $\begin{array}{l}1000 \text { Tane } \\
\text { Ağırlığı } \\
\text { (g) }\end{array}$ & $\begin{array}{l}\text { Tohum } \\
\text { Verimi } \\
\left(\mathrm{kg} \mathrm{da}^{-1}\right)\end{array}$ & $\begin{array}{c}\text { Kabuk } \\
\text { Oranı } \\
(\%)\end{array}$ & $\begin{array}{c}\text { Yağ } \\
\text { Oranı } \\
(\%)\end{array}$ & $\begin{array}{c}\text { Yă̆ } \\
\text { Verimi } \\
\left(\mathrm{kg} \mathrm{da}^{-1}\right)\end{array}$ \\
\hline 1 & EC/ol-1 & 77.86 a-e & $7.20 \mathrm{bc}$ & 12.55 & $2.38 \mathrm{~d}$ & $42.59 \mathrm{a}-\mathrm{d}$ & $128.30 \mathrm{efg}$ & $44.00 \mathrm{~b}$ & $31.86 \mathrm{~g}$ & $40.60 \mathrm{f}$ \\
\hline 2 & EC/ol-2 & $77.11 \mathrm{cde}$ & $6.71 \mathrm{cde}$ & 11.61 & $2.39 \mathrm{~cd}$ & $43.12 \mathrm{a}-\mathrm{d}$ & $127.26 \mathrm{fg}$ & $39.20 \mathrm{de}$ & $31.67 \mathrm{~g}$ & $40.43 \mathrm{f}$ \\
\hline 3 & EC/ol-3 & 79.53 a-e & $7.20 \mathrm{bc}$ & 12.60 & $2.27 \mathrm{e}$ & $44.06 \mathrm{ab}$ & 143.0 & 38.46 ef & $32.07 \mathrm{~g}$ & 45.88 ef \\
\hline 4 & EC/ol-4 & $80.56 \mathrm{abc}$ & $6.90 \mathrm{c}$ & 11.48 & $2.42 \mathrm{~cd}$ & $42.56 \mathrm{a}-\mathrm{d}$ & $149.53 \mathrm{c}-\mathrm{f}$ & $40.00 \mathrm{~d}$ & $32.29 \mathrm{~g}$ & $48.26 \mathrm{def}$ \\
\hline 5 & EC/ol-5 & 79.35 a-e & $6.98 \mathrm{c}$ & 12.68 & $2.49 \mathrm{ab}$ & $42.56 \mathrm{a}-\mathrm{d}$ & $150.40 \mathrm{c}-\mathrm{f}$ & $35.40 \mathrm{~h} 1$ & $35.17 \mathrm{~cd}$ & $52.92 \mathrm{cde}$ \\
\hline 6 & EC/ol-6 & 77.65 b-e & 7.78 & 12.63 & $2.49 \mathrm{ab}$ & $41.62 \mathrm{~b}-\mathrm{e}$ & 143.1 & 35.001 & $34.56 \mathrm{de}$ & $50.09 \mathrm{def}$ \\
\hline 7 & EC/ol-7 & $76.78 \mathrm{def}$ & $6.83 \mathrm{~cd}$ & 11.70 & $2.44 \mathrm{bc}$ & $41.47 \mathrm{cde}$ & $156.06 \mathrm{cde}$ & $36.60 \mathrm{gh}$ & $36.49 \mathrm{ab}$ & $56.93 \mathrm{bcd}$ \\
\hline 8 & EC/ol-8 & $78.77 \mathrm{a}-\mathrm{e}$ & $6.05 \mathrm{ef}$ & 13.48 & $2.39 \mathrm{~cd}$ & $43.48 \mathrm{a}-\mathrm{d}$ & $187.80 \mathrm{ab}$ & $39.40 \mathrm{de}$ & $34.04 \mathrm{e}$ & $63.92 \mathrm{~b}$ \\
\hline 9 & EC/ol-9 & $81.40 \mathrm{a}$ & $7.01 \mathrm{bc}$ & 13.05 & $2.31 \mathrm{e}$ & $41.23 \mathrm{de}$ & $156.60 \mathrm{~cd}$ & $41.60 \mathrm{c}$ & $32.72 \mathrm{fg}$ & $52.13 \mathrm{de}$ \\
\hline 10 & EC/ol-10 & $79.81 \mathrm{a}-\mathrm{d}$ & $5.80 \mathrm{f}$ & 12.13 & $2.28 \mathrm{e}$ & $43.78 \mathrm{abc}$ & $120.73 \mathrm{~g}$ & $40.20 \mathrm{~cd}$ & $33.56 \mathrm{ef}$ & $40.47 \mathrm{f}$ \\
\hline 11 & EC/ol-11 & 77.15 cde & $6.15 \mathrm{def}$ & 11.36 & $2.30 \mathrm{e}$ & $41.02 \mathrm{de}$ & $128.66 \mathrm{~d}-\mathrm{g}$ & $37.80 \mathrm{fg}$ & $35.28 \mathrm{~cd}$ & $45.07 \mathrm{ef}$ \\
\hline 12 & Dinçer 5-18-1 & $80.80 \mathrm{ab}$ & $4.60 \mathrm{~g}$ & 11.23 & $2.28 \mathrm{e}$ & $45.10 \mathrm{a}$ & $174.10 \mathrm{bc}$ & $48.93 \mathrm{a}$ & 29.991 & $51.50 \mathrm{de}$ \\
\hline 13 & PI 603208 & $73.36 \mathrm{f}$ & $8.35 \mathrm{a}$ & 14.35 & $2.54 \mathrm{a}$ & $36.01 \mathrm{f}$ & $122.46 \mathrm{fg}$ & 34.331 & $37.27 \mathrm{a}$ & 45.38 ef \\
\hline 14 & Olas & $72.35 \mathrm{~g}$ & $6.86 \mathrm{~cd}$ & 14.15 & $2.51 \mathrm{a}$ & $42.36 \mathrm{bcd}$ & $177.80 \mathrm{bc}$ & $37.66 \mathrm{fg}$ & $35.78 \mathrm{bc}$ & $63.63 \mathrm{bc}$ \\
\hline 15 & Asol & $76.35 \mathrm{ef}$ & $7.11 \mathrm{bc}$ & 12.63 & $2.50 \mathrm{ab}$ & $39.56 \mathrm{e}$ & $221.93 \mathrm{a}$ & 38.60 ef & $37.10 \mathrm{a}$ & $82.38 \mathrm{a}$ \\
\hline & Genotip & $* *$ & $* *$ & ns & $* *$ & $* *$ & $* *$ & $* *$ & $* *$ & $* *$ \\
\hline & CV & 3.71 & 13.40 & 12.17 & 4.00 & 5.58 & 19.57 & 9.35 & 6.44 & 22.56 \\
\hline
\end{tabular}

Aspirde tohum verimini belirleyen en önemli kriterlerinden birisi de 1000 tane ağırllğıdır (Weiss, 2000). Aspirde 1000 tane ağırlı̆̆ı yüksek kalıtım derecesi gösterdiğinden dolayı, bu özellik bakımından yapılacak seleksiyonlarda yüksek tohum verimine sahip hatların oluşturulmasına katkı sağlayacaktır (Pahlavani ve ark., 2007). Araştırmada melez genotipler arasında en yüksek 1000 tane ağırlığ $44.06 \mathrm{~g}$ ile EC/ol-3 genotipinden elde edilmiştir (Tablo 3). Yerel çeşitler ve ebeveynler arasında ise en yüksek 1000 tane ağırlı̆̆ı ana ebeveyn olan Dinçer 5-18-1 çeşidinden elde edilmiştir (45.10 g). Yapılan araştırmalarda 1000 tane ağırlığını Erbaş (2007) 33.6-52.1 g arasında, Katar ve ark. (2015) 42.23-51.78 g arasında, Culpan ve Arslan (2018) 40.90-54.95 g arasında, Kobuk ve ark. (2019) 31.15-49.10 g arasında değiştiğini bildirmişlerdir. Ayrıca aspirde 1000 tane ağırlığının 50 g'ın üzerine çıkarılmasıyla tohum ve yağ veriminin artırabileceği rapor edilmiştir (Weiss, 2000). 
Melez aspir genotiplerinin tohum verimi değerleri $120.73-187.80 \mathrm{~kg} \mathrm{da}^{-1}$ arasında değişmiş ve en yüksek tohum verimi EC/ol-8 genotipinden elde dilmiştir $\left(187.80 \mathrm{~kg} \mathrm{da}^{-1}\right)$. Aspirde en önemli sslah amacı tohum verimini artırmaktır. Aspirde tohum veriminin genetiğinde birden fazla eklemeli gen rol aldığından dolayı kalıtım derecesi düşüktür (Weiss, 2000; Erbaş, 2012). Ayrıca tohum verimi, bir çeşit özelliği olmasının yanı sıra iklim koşulları ve kültürel uygulamalardan önemli ölçüde etkilenmektedir (Siddiqui ve Oad, 2006). Yapılan araştırmalarda aspirde tohum verimi değerlerini Uysal ve ark. (2006) $55.0-80.3 \mathrm{~kg} \mathrm{da}^{-1}$ arasında, (Baydar ve Erbaş, 2016), $74.5-225.3 \mathrm{~kg}$ $\mathrm{da}^{-1}$ arasinda, Arslan ve Culpan (2020) $\mathrm{F}_{2}$ kademesineki 14 aspir genotipinde 98.23-171.26 kg da ${ }^{-1}$ arasinda, Şenateş ve Erbaş (2020) F8 generasyonuna kadar tek tohum nesli seleksiyon yöntemi ile ulaştırılan 68 adet hattın tohum veriminin 30.2-252.6 kg da $\mathrm{kg}^{-1}$ arasında değiştiğini bildirmişlerdir. Ayrıca Baydar ve Erbaş (2020), Dinçer 518-1 x Montola 2000 çeşitlerinin melezlenmesinden elde edilen ve 2019 yılında tescil ettirilen Olein, Zirkon ve Safir çeşitlerinin tarla denemelerinde elde edilen tohum verimi değerlerinin sırasıyla $246.5,271.8$ ve $252.4 \mathrm{~kg} \mathrm{da}$ ${ }^{1}$ olduğunu bildirmişlerdir.

Aspirde tohum kabuğu inceliği istenilen bir seleksiyon kriteridir. Kabuk inceldikçe kabuk oranı azalmakta, dolayısıyla iç oranı ve yağ oranı artmaktadır (Mündel ve Bergman, 2010). Çalışmada melez genotiplerin kabuk oranı değerleri \% 35.00-44.00 arasında değişmiş ve en düşük kabuk oranı EC/ol-6 genotipinden elde edilmiştir (Tablo 3). Rudra Naik ve ark. (2009) $\mathrm{F}_{2}$ ve $\mathrm{F}_{3}$ kademelerinde kabuk oranına fenotipik etkinin az olduğunu ve oluşan çeşitliliğin genotipten kaynaklandığını bildirmiş̧lerdir. Baydar ve Erbaş (2016), 64 adet aspir hattında ve bunların ebeveynlerinde kabuk oranını \% 46.2-53.6 arasında, Kobuk ve ark. (2019) bazı aspir hatları ve çeşitlerinin kabuk oranı değerlerini \% 42.68-52.90 arasında, Arslan ve Culpan (2020) $F_{2}$ kademesindeki 14 aspir genotipinin kabuk oranını 40.42-48.67 arasında belirlemiş̧lerdir. Kabuk oranı düşük aspir genotiplerinin ileri generasyonlara taşınması ümitvar hatların belirlenmesinde büyük önem taşımaktadır.

Aspir melez ve ebeveynlerinin yağ oranı değerleri \% 29.99-37.27 arasında değişmiş ve en yüksek yağ oranı baba ebeveyn olan PI 603208 genotipinden elde edilmiştir (\% 37.27). Melez genotiplerde ise en yüksek yağ oranı EC/ol-7 (\% 36.49) genotipinde saptanmıştır (Tablo 3). Johnson ve ark. (1999), 797 aspir genotipinde yă oranını \%13-46 arasında, Nabloussi ve ark. (2008) \% 23.36-47.53 arasında, Baydar ve Erbaş (2016) \% 30.0036.70 arasında, Erbaş ve ark. (2016) \% 22.6-33.8 arasında, Arslan ve Culpan (2018) \% 15.58-37.42 arasında, Kobuk ve ark. (2019) \% 25.78-35.16 arasında değiştiğini bildirmişlerdir. Aspirde yağ oranı yüksek oranda kalıtım derecesine sahip olduğundan dolayı (Ramachandram ve Goud, 1981) hat ve döllerde belirlenen yağ oranları olası bir yabancı döllenme olmadığı takdirde sonraki generasyonlara aktarılabilmekte ve seleksiyonda başarı şansı artırılabilmektedir (Şenateş ve Erbaş, 2020). Bu sayede yüksek yağ oranına sahip melez genotipler izole edilerek ileri generasyonlara taşınacak ve yağ oranı yüksek ümitvar hatlar elde edilebilecektir.

Yapılan araştırmada en yüksek yağ verimi Asol çeşidinden elde edilmiştir $\left(82.38 \mathrm{~kg} \mathrm{da}^{-1}\right)$. Melez genotiplerde ise en yüksek yağ verimi EC/ol-8 (63.92 $\mathrm{kg} \mathrm{da}^{-1}$ ) genotipinde belirlenmiştir (Tablo 3). Paşa (2008) yazlık ve kışlık olarak ekilen aspir genotiplerinin yağ verimlerini $43.3-103.8 \mathrm{~kg} \mathrm{da}^{-1}$ arasında, Kaya ve ark. (2015) bazı aspir genotiplerinin yağ verimi değerlerini 37.0-48.9 kg/da arasında, Arslan ve Culpan (2018) yaptıkları çalışmada bu değerlerin 1.3-67.97 kg da ${ }^{-1}$ arasında olduğunu rapor etmişlerdir. Ayrıca aspirde yağ veriminin çevre koşullarından kolaylıkla etkilenebileceği bildirilmiştir (Erbaş, 2012). Yağlı tohumların yağ asitleri kompozisyonu çeşide ve türe göre değişmekle birlikte, genetik, ekolojik, morfolojik, fizyolojik ve kültürel faktörlere bağlı olarak oldukça değişkenlik gösterebilmektedir (Karaca ve Aytaç, 2007; Duru ve Bozdoğan Konuşkan, 2014). Aspir, yağlı tohumlar arasında yağ asitleri komposizyonu bakımından geniş varyasyon gösteren oleik ve linoleik tipleri bulunan bir bitkidir (Bergman ve ark., 1997; Arslan ve Küçük, 2005). Aspir melez ve ebeveynlerin yağ asitleri kompozisyonu Tablo 4'te verilmiştir. 


\begin{tabular}{|c|c|c|c|c|c|c|}
\hline \multicolumn{7}{|c|}{$\begin{array}{l}\text { Tablo 4. Aspir genotip ve melezlerinin yă asitleri komposiyonu } \\
\text { Tablo 4. Fatty acid composition of safflower genotypes and hybrids }\end{array}$} \\
\hline \multirow[b]{2}{*}{ No } & \multirow[b]{2}{*}{ Hat/Çeşit } & \multicolumn{5}{|c|}{ Yağ Asitleri Komposizyonu (\%) } \\
\hline & & $\begin{array}{c}\text { Oleik } \\
C_{18: 1} \\
\end{array}$ & $\begin{array}{c}\text { Linoleik } \\
\mathrm{C}_{18: 2} \\
\end{array}$ & $\begin{array}{c}\text { Palmitik } \\
\mathrm{C}_{16: 0} \\
\end{array}$ & $\begin{array}{c}\text { Stearik } \\
\text { C18:0 }\end{array}$ & $\begin{array}{c}\text { Diğger } \\
\text { Yă̆ Asit. }\end{array}$ \\
\hline 1 & EC/ol-1 & 24.48 & 62.73 & 8.85 & 1.99 & 1.95 \\
\hline 2 & EC/ol-2 & 66.24 & 23.44 & 6.15 & 2.05 & 2.12 \\
\hline 3 & EC/ol-3 & 31.75 & 55.76 & 7.28 & 2.26 & 2.95 \\
\hline 4 & EC/ol-4 & 20.05 & 70.31 & 4.65 & 2.00 & 2.99 \\
\hline 5 & EC/ol-5 & 50.74 & 37.17 & 5.00 & 3.64 & 3.45 \\
\hline 6 & EC/ol-6 & 33.47 & 50.12 & 9.36 & 2.65 & 4.64 \\
\hline 7 & EC/ol-7 & 63.09 & 29.60 & 4.17 & 1.64 & 1.50 \\
\hline 8 & EC/ol-8 & 42.14 & 47.88 & 7.00 & 2.34 & 0.64 \\
\hline 9 & EC/ol-9 & 18.65 & 70.01 & 6.85 & 2.95 & 1.45 \\
\hline 10 & EC/ol-10 & 31.68 & 56.54 & 5.99 & 2.46 & 3.33 \\
\hline 11 & EC/ol-11 & 59.79 & 29.24 & 6.22 & 2.50 & 2.25 \\
\hline 12 & Dinçer & 11.65 & 77.08 & 7.41 & 2.14 & 1.72 \\
\hline 13 & PI 603208 & 70.01 & 18.82 & 6.68 & 2.50 & 1.99 \\
\hline 14 & Olas & 74.68 & 13.87 & 4.42 & 2.35 & 4.68 \\
\hline 15 & Asol & 73.02 & 15.85 & 5.46 & 1.28 & 4.39 \\
\hline
\end{tabular}

Araştırma sonuçlarına göre melez genotiplerin oleik yağ asidi oranı \% 18.65-66.24 arasında değişmiş ve en yüksek oleik yağ asidi oranı EC/ol-2 (\% 66.24) genotipinden elde edilmiştir (Tablo 4). Golkar ve ark. (2011) oleik asidin kalıtımında eklemeli genlerin etkili olduğunu ve yüksek kalıtım derecesi (geniş ve dar anlamda sırasıyla, F1'de 0.92-0.81 ve F2'de 0.93-0.73) gösterdiğini bildirmişlerdir. Nitekim EC/ol-2, EC/ol-5, EC/ol-7 ve EC/ol-11 melez genotipleri F2 kademesinde oleik asit oranları bakımından Golkar ve ark. (2011)'ın araştırmasını desteklemektedir. Aspir bitkisinde linoleik alleli (Ol) oleik alleli (ol) üzerine baskındır. Oleik asit sentezinden sorumlu resesif allel genler $(o l)$ döllenme sırasında gelişen embriyoda linoleik sentezinden sorumlu dominant allel genler $(\mathrm{Ol})$ tarafindan bastırılarak oleik asidin azalmasına neden olmaktadır (Hamdan ve ark., 2009; Velasco ve ark., 2012). Aspirde yabancı döllenme sonucu linoleik tip bitkilerin polenleriyle döllenmiş oleik tip bitkilerin tohumlarında oleik asit oranı azalmaktadır (Baydar, 2016). Bu nedenle, oleik asitçe zengin aspir hat ve döllerinin ileri generasyonlara taşınabilmesi için mutlaka yabancı tozlaşma ve döllenmeye karşı izole edilmelidir. Ayrıca aspirde farklı olgunlaşma dönemlerinde hasat edilen tohumlarda yağ asitleri kompozisyonu bakımından farklılıklar tespit edilmiştir (Geçgel ve ark., 2007).

\section{Sonuç}

Ülkemizin hemen hemen her bölgesi aspir tarımı yapılmasına elverişli olmasına rağmen, ekim alanlarında ve üretiminde son yıllarda önemli artışlar görülememiştir. Aspir tarımının yaygınlaştırılabilmesi, ekiminin teşvik edilebilmesi ve ayrıca her yıl giderek artan bitkisel yağ açığının artmasına karşı çeşit sayısının artırılmasına ihtiyaç duyulmaktadır. Geliştirilecek olan aspir çeşit ve hatlarının da farklı ekolojik koşullarda stabil bir üretime izin verecek şekilde adaptasyon yeteneğinin ve verim performansının yüksek olması gerekmektedir. Ayrıca sağlık, beslenme ve yağ kalitesi açısından yararlarının anlaşılmasından dolayı son yıllarda yüksek oleik asit içeren bitkisel yağların üretimi ve tüketimi tercih haline gelmiştir. Bu sebeple oleik asit içeriği yüksek olan aspir çeşitlerinin geliştirilmesi de ayrıca önem arz etmektedir. Yürütülen bu çalışma kapsamında yüksek yağ oranı, tohum verimi ve oleik yağ asidi içeriği bakımından belirlenen ıslah amaçları doğrultusunda $\mathrm{F}_{2}$ kademesindeki 5 adet genotipin (EC/ol 5, EC/ol 6, EC/ol 7, $\mathrm{EC} / \mathrm{ol} 8 \mathrm{ve} \mathrm{EC} / \mathrm{ol}$ 11) diğer genotiplerden üstün olduğu belirlenmiştir. Ayrıca diğer genotipler ile birlikte ilerleyen kademelerde $\left(\mathrm{F}_{3}\right.$ ve $\mathrm{F}_{4}$ ) olası bir yabancı döllenmeyi de engelleyerek hem stabil olanlar hem de ümitvar olan hatlar belirlenecektir. 


\section{Kaynakça}

Adalı, M., Öztürk, Ö. (2016). Konya koşullarında bazı aspir çeşitlerinin verim ve verim unsurlarının belirlenmesi. Selçuk Tarım Bilimleri Dergisi 3 (2): 233-237.

Arslan, B., Küçük, M. (2005). Oil content and fatty acids composition of some safflower cultivars in Van (Turkey). 6th International Safflower Conference. 6-10 June, P.167-174. Istanbul, Turkey.

Arslan, B., Culpan, E. (2018). Identification of suitable safflower genotypes for the development of new cultivars with high seed yield, oil content and oil quality. Azarian Journal of Agriculture 5 (5): 133-141.

Arslan, B., Culpan, E. (2020). Melezleme ile geliştirilmiş bazı aspir (Carthamus tinctorius L.) genotiplerinin tarımsal ve teknolojik özelliklerinin belirlenmesi. Yüzüncü Yll Üniversitesi Tarım Bilimleri Dergisi 30 (4): 742-750. doi: 10.29133/yyutbd.703793

Aslantaş, Ş., Akınerdem, F. (2020). Bazı kışlık aspir çeşitlerinde farklı ekim zamanlarının verim, verim unsurları ve kalite üzerine etkileri. Bahri Dăğdaş Bitkisel Araştırma Dergisi 9 (1): 21-28.

Atan, M., Şahin, C., İşler, N. (2019). Hatay koşullarında farklı aspir çeşitlerinde verim, verim unsurları ve yağ içeriğinin belirlenmesi. Kahramanmaraş Sütçü İmam Üniversitesi Tarım ve Doğa Dergisi 22 (5): 678-684. doi: 10.18016/ksutarimdoga.vi.537252

Babaoğlu, M., Güzel, M. (2015). Safflower (Carthamus tinctorius L.) breeding activities at Trakya Agricultural Research Institute. Ekin Journal of Crop Breeding and Genetics 1 (1): 20-25.

Baydar, H. (2016). Yağ bitkilerinde oleik asitçe zengin çeşitlerin ıslahında yaşanan gelişmeler. Türkiye Tohumcular Birliği Dergisi 20 : 34-37.

Baydar, H., Erbaş, S. (2016). Aspir (Carthamus tinctorius L.)'de verim, yağ ve oleik asit içeriği yüksek hat geliştirme ıslahı. Tarla Bitkileri Merkez Araştırma Enstitüsü Dergisi 25 (Özel Say1-2): 155-161.

Baydar, H., Erbaş, S. (2020). Yerli ve milli aspir çeşitlerimiz: Olein, Zirkon ve Safir. Isparta Uygulamalı Bilimler Üniversitesi Ziraat Fakültesi Dergisi, Türkiye 13. Ulusal, I. Uluslararası Tarla Bitkileri Kongresi Özel Sayısı, 233-237.

Bayramin, S. (2006). Aspir (Carthamus tinctorius L.) - Kolza (Brassica napus spp. oleifera L.) tarımı ve 1slahı. Tarla Bitkileri Merkez Araştırma Enstitüsü Dergisi 15 (1-2): 74-85.

Bergman, J.W., Flynn, C.R., Johnson, R.C. (1997). Evaluation of safflower accessions for oil and meal quality factors. 4th International Safflower Conference. 2-7 June, P.232-234, Bari, Italy.

Bergman, J.W., Riveland, N.R., Flynn, C.R., Carlson, G., Wichman, D. (2000). Registration of 'Montola 2001' safflower. Crop Science 40: 573-574.

Culpan, E., Arslan, B. (2018). Salisilik asit uygulamasının aspir (Carthamus tinctorius L.) çeşitlerinin verim ve bazı kalite özelliklerine etkisinin araştırılması. Akademik Ziraat Dergisi 7 (2): 173-178. doi: 10.29278/azd.476336

Çamaş, N., Ayan, A.K., Çırak, C. (2005). Relationships between seed yield and some characters of safflower (Carthamus tinctorius L.) cultivars grown in the Middle Black Sea conditions. 6th International Safflower Conference. 6-10 June, P.193-198. Istanbul, Turkey.

Çamaş, N., Esendal, E. (2006). Estimates of broad-sense heritability for seed yield and yield components of safflower (Carthamus tinctorius L.). Hereditas 143: 55-57.

Duru, S., Bozdoğan Konuşkan, D. (2014). Bitkisel yağlarda oleik asit miktarının arttırılması ve yağ kalitesi üzerine etkileri. Glda 39 (6): 1-7. doi: $10.15237 /$ gida.GD14026

Emongor, V. (2010). Safflower (Carthamus tinctorius L.) the underutilized and neglected crop: A review. Asian Journal of Plant Sciences 9: 299-306.

Erbaş, S. (2007). Aspirde (Carthamus tinctorius L.) sentetik erkek kısırlığı tekniği ile elde edilmiş melez populasyonlarından hat geliştirme olanaklart. (Yüksek Lisans Tezi) Süleyman Demirel Üniversitesi Fen Bilimleri Enstitüsü, Isparta.

Erbaş, S., Tonguç, M., Şanlı, A. (2016). Variations in the agronomic and quality characteristics of domestic and foreign safflower (Carthamus tinctorius L.) genotypes. Turkish Journal of Field Crops 21 (1): 110-119. doi: 10.17557/tjfc.56268

Erbaş, S. (2012). Melezleme ıslahı ile tohum verimi, yağ ve oleik asit içeriği yüksek aspir (Carthamus tinctorius L.) hatlarının geliştirilmesi. (Doktora Tezi) Süleyman Demirel Üniversitesi Fen Bilimleri Enstitüsü, Isparta.

Gecgel, U., Demirci, M., Esendal, E., Tasan, M. (2007). Fatty acid composition of the oil from developing seeds of different varieties of safflower (Carthamus tinctorius L.). Journal of the American Oil Chemists Society 84 (1): 47-54. doi: 10.1007/s11746-006-1007-3

Golkar, P., Arzani, A., Rezaei, A.M. (2011). Genetic analysis of oil content and fatty acid composition in safflower (Carthamus tinctorius L.). Journal of the American Oil Chemists Society 88: 975-982. doi: 10.1007/s11746-011-1758-3

Gürsoy, M., Başalma, D., Nofouzi, F. (2018). Farklı sıra arası ve sıra üzeri mesafelerin aspir (Carthamus tinctorius L.) çeşitlerinin verim ve verim ögelerine etkileri. Selçuk Tarım ve Glda Bilimleri Dergisi 32 (1): 20-28. doi: 10.15316/SJAFS.2018.59

Hamdan, Y.A.S., Perez-Vich, B., Velasco, L., Fernandez-Martinez, J.M. (2009). Inheritance of high oleic acid content in safflower. Euphytica 168: 61-69. doi: 10.1007/s10681-008-9879-y 
Hatipoğlu, H., Arslan, H., Karakuş, M., Köse, A. (2012). Şanlıurfa koşullarında farklı aspir çeşitlerinin (Carthamus tinctorius L.) uygun ekim zamanlarının belirlenmesi. Uludağ Üniversitesi Ziraat Fakültesi Dergisi 26 (1): 1-16.

Johnson, R.C., Bergman, J.W., Flynn, C.R. (1999). Oil and meal characteristics of core and non-core safflower accessions from the USDA collection. Genetic Resources and Crop Evolution 46: 611-618.

Karaca, E., Aytaç, S. (2007). Yağ bitkilerinde yă̆ asitleri kompozisyonu üzerine etki eden faktörler. Anadolu Tarım Bilimleri Dergisi (OMÜ Ziraat Fakültesi Dergisi) 22 (1): 123-131.

Katar, D., Arslan, Y., Kodaş, R., Subaşı, İ., Mutlu, H. (2014). Bor uygulamalarının aspir (Carthamus tinctorius L.) bitkisinde verim ve kalite unsurları üzerine etkilerinin belirlenmesi. Tekirdağ Ziraat Fakültesi Dergisi 11 (2): 71-79.

Katar, D., Arslan, Y., Subaşı, İ., Kodaş, R., Katar, N. (2015). Bölünerek uygulanan azotlu gübrelerin aspir (Carthamus tinctorius L.) bitkisinde verim ve verim unsurları üzerine etkisi. Tekirdă̆ Ziraat Fakültesi Dergisi 15 (2): 11-20.

Kaya, M., Bayramin, S., Kulan, E., Özaşık, İ. (2015). Bazı ileri aspir hatlarının Eskişehir koşullarındaki performansları. Uludağ Üniversitesi Ziraat Fakültesi Dergisi 29 (1): 57-66.

Kızıl, S. (2002). Diyarbakır ekolojik koşullarında aspir (Carthamus tinctorius L.)'de uygun ekim zamanının belirlenmesi üzerine bir çalışma. Anadolu Ege Tarımsal Araştırma Enstitüsü Dergisi 12 (1): 37-50.

Knowles, P.F., Hill, A.B. (1964). Inheritance of fatty acid content in the seed oil of a safflower introduction from Iran. Crop Science 4: 406409.

Kobuk, M., Ekinci, K., Erbaş, S. (2019). Aspir (Carthamus tinctorius L.) genotiplerinin fiziksel ve kimyasal özelliklerinin belirlenmesi. Kahramanmaraş Sütçü Imam Üniversitesi Tarım ve Doğa Dergisi 22 (1): 89-96. doi: 10.18016/ksutarimdoga.vi.455408

Köse, A., Bilir, Ö. (2017). Aspir bitkisinde (Carthamus tinctorius L.) farklı sıra arası mesafelerin ve ekim normunun taç yaprak verimi ve bazı bitkisel özellikler üzerine etkisi. Türk Tarım ve Doğa Bilimleri Dergisi 4 (1): 40-47.

Mündel, H.H., Bergman, J.W. (2010). Safflower. In J. Vollmann, \& I. Rajcan (Eds.), Oil Crops, Handbook of Plant Breeding. Springer, Berlin.

Nabloussi, A., El Fechtali, M., Lyagoubi, S. (2008). Agronomic and technological evaluation of a world safflower collection in Moroccan conditions. 7th International Safflower Conference. 3-6 November, Wagga Wagga, New South Wales, Australia.

Pahlavani, M.H., Saeidi, G., Mirlohi, A.F. (2007). Genetic analysis of seed yield and oil content in safflower using $F_{1}$ and $F_{2}$ progenies of diallel crosses. International Journal of Plant Production 2: 129-140.

Paşa, C. (2008). Klşlık ve yazlık ekimin aspir (Carthamus tinctorius L.) bitkisinin verimi ve bitkisel özeliklerine etkisi. (Yüksek Lisans Tezi) Namık Kemal Üniversitesi Fen Bilimleri Enstitüsü, Tekirdağ.

Pearl, S.A., Bowers, J.E., Reyes-Chin-Wo, S., Michelmore, R., Burke, J.M. (2014). Genetic analysis of safflower domestication. BMC Plant Biology 14: 43. doi: 10.1186/1471-2229-14-43

Pinto, A.C., Guarieiro, L.L.N., Rezende, M.J.C. (2005). Biodiesel: An overview. Journal of Brazilian Chemical Society 16: 1313-1330.

Ramachandram, M., Goud, J.V. (1981). Genetic analysis of seed yield, oil content and their components in safflower (Carthamus tinctorius L.). Theoretical and Applied Genetics 60: 191-195.

Rudra Naik, V., Bentur, G.M., Salimath, P.M., Parameshwarappa, K.G. (2009). Introgression of non spiny and high oil content in adapted generations of safflower (Carthamus tinctorius L.). Karnataka Journal of Agricultural Sciences 22 (1): 39-43.

Siddiqui, M.H., Oad, F.C. (2006). Nitrogen requirement of safflower (Carthamus tinctorius L.) for growth and yield traits. Asian Journal of Plant Sciences 5 (3): 563-565. doi: 10.3923/ajps.2006.563.565

Şenateş, A., Erbaş, S. (2020). Tek tohum nesli seleksiyon yöntemi ile geliştirilen aspir (Carthamus tinctorius L.) hatlarının tarımsal ve teknolojik özelliklerinin belirlenmesi. Süleyman Demirel Üniversitesi Fen Bilimleri Enstitüsü Dergisi 24 (1): 143-151. doi: $10.19113 /$ sdufenbed.645643

Tunçtürk, M., Arslan, B., Çiftçi, V. (2005). Relationships among traits using correlation and path coefficient analysis in safflower (Carthamus tinctorius L.). 6th International Safflower Conference. 6-10 June, P.199-204. Istanbul, Turkey.

Uysal, N., Baydar, H., Erbaş, S. (2006). Isparta popülasyonundan geliştirilen aspir (Carthamus tinctorius L.) hatlarının tarımsal ve teknolojik özelliklerinin belirlenmesi. SDÜ Ziraat Fakültesi Dergisi 1 (1): 52-63.

Velasco, L., Fischer, M. Fernandez-Martinez, J.M. (2012). Short communication. Estimation of cross-fertilization rate in safflower (Carthamus tinctorius L.). Spanish Journal of Agricultural Research 10 (1): 155-159. doi: 10.5424/sjar/2012101-198-11

Weiss, E.A. (2000). Oilseed Crops: Safflower (2nd ed.). Blackwell Science, Oxford. 